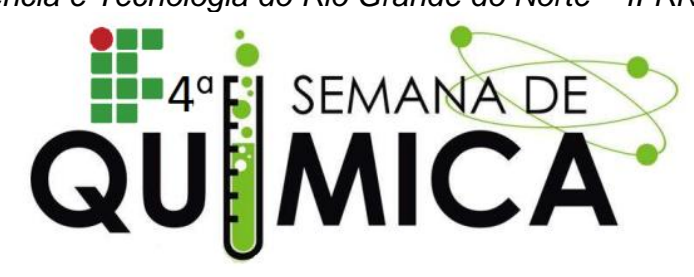

\title{
ANÁLISE FÍSICO-QUÍMICA EM SUCOS INDUSTRIALIZADOS COMERCIALIZADOS EM NOVA CRUZ/RN
}

\author{
ANJOS, E. E. P. (IC) (IFRN-NC); LINS, F. C. C. (IC) (IFRN-NC); SILVA, A. C. O. (PQ) (IFRN-NC)
}

Palavras Chave: Acidez titulável, Análise físico-química, sucos industrializados.

\section{INTRODUÇÃO}

As análises físico-químicas de sucos industrializados são importantes pois, trazem informações necessárias para o consumidor verificar se o produto que ele adquire estão dentro de padrões estabelecidos nas normas vigentes. Os dados obtidos foram comparados com as normas do Ministério da Agricultura, Pecuária e Abastecimento ${ }^{[2]}$, que representa a legislação brasileira em vigor.

\section{METODOLOGIA}

As amostras de suco avaliadas foram classificadas em marca A e B e selecionado três sabores. Para cada amostra foi feita uma diluição de $10 \mathrm{~mL}$ em $50 \mathrm{~mL}$ de água destilada. Em seguida foi realizada a titulação com $\mathrm{NaOH}$ como titulante estando a amostra em constante agitação magnética até atingir a coloração rósea no titulado. $O$ procedimento foi feito em triplicata para cada amostra.

\section{RESULTADOS E DISCUSSÕES}

Para o cálculo do teor de acidez titulável em gramas por $100 \mathrm{~mL}$ foi utilizada a seguinte equação:

$A T=\frac{V o \cdot M \cdot f \cdot P M}{V \cdot 10 \cdot n}$

Onde,

AT $=$ Acidez titulável

Vo = Volume da solução de $\mathrm{NaOH}$ gasto na titulação, em Ml

$\mathrm{M}=$ Molaridade da solução de $\mathrm{NaOH}$

$f=$ Fator de concentração da solução de $\mathrm{NaOH}$

$\mathrm{PM}=$ Massa molar do ácido cítrico ou tartárico $\mathrm{n}=$ número de hidrogênios ionizáveis do ácido cítrico ou tartárico

Os resultados obtidos para acidez titulável, condutividade e $\mathrm{pH}$ estão expressos na tabela 1.

Tabela 1 - Dados para teor de acidez titulável, condutividade e $\mathrm{pH}$ nos sucos.

\begin{tabular}{c|c|c|c|c|c}
\hline \multirow{2}{*}{$\begin{array}{c}\text { Sabor do } \\
\text { suco }\end{array}$} & Marca & $\begin{array}{c}\text { Acidez } \\
\text { titulável }\end{array}$ & $\begin{array}{c}\text { Norma } \\
\text { Padrão }\end{array}$ & $\begin{array}{c}\text { Condutividade } \\
(\mu \mathrm{S} / \mathrm{cm})\end{array}$ & $\mathrm{pH}$ \\
\hline \multirow{2}{*}{ Laranja } & $\mathrm{A}$ & 0,2143 & $\begin{array}{c}\text { Max } \\
7,00\end{array}$ & $771,2 \mu \mathrm{S} / \mathrm{cm}$ & 2,94 \\
\cline { 2 - 6 } & $\mathrm{B}$ & 0,4165 & $\begin{array}{c}\text { Max } \\
7,00\end{array}$ & $1212,0 \mu \mathrm{S} / \mathrm{cm}$ & 2,90 \\
\hline \multirow{2}{*}{ Maracujá } & $\mathrm{A}$ & 0,2002 & $\begin{array}{c}\text { Min de } \\
0,27\end{array}$ & $800,1 \mu \mathrm{S} / \mathrm{cm}$ & 2,93 \\
\cline { 2 - 6 } & $\mathrm{B}$ & 0,3681 & $\begin{array}{c}\text { Min de } \\
0,27\end{array}$ & $1231,0 \mu \mathrm{S} / \mathrm{cm}$ & 3,03 \\
\hline \multirow{2}{*}{ Uva } & $\mathrm{A}$ & 0,0940 & $\begin{array}{c}\text { Max } \\
0,41\end{array}$ & $693,7 \mu \mathrm{S} / \mathrm{cm}$ & 3,03 \\
\cline { 2 - 6 } & $\mathrm{B}$ & 0,2350 & $\begin{array}{c}\text { Max } \\
0,41\end{array}$ & $914,9 \mu \mathrm{S} / \mathrm{cm}$ & 2,89 \\
\hline
\end{tabular}

Fonte: MAPA (2000)

\section{CONCLUSÃO}

Todas as amostras obtidas, com exceção do suco de maracujá da marca $A$, estão dentro dos padrões estabelecidos pelo MAPA (2000). Dessa forma, os resultados obtidos mostram que os padrões para acidez titulável para ácido cítrico/tartárico estão dentro das normas da legislação brasileira.

\section{REFERÊNCIAS}

${ }^{1}$ FREIRE, M. T. A. Caracterização físico-química, microbiológica e sensorial de polpa de cupuaçu congelada (Theobroma grandiflorum Schum). Pirassununga/SP: USP, 2009.

${ }^{2}$ MINISTÉRIO DA AGRICULTURA, PECUÁRIA E ABASTECIMENTO. Instrução normativa no 12 , de 4 de setembro de 2003. - Brasília/DF: MAPA, 2003. 